\title{
IMPLEMENTING A UNIVERSITY LEARNING CONSORTIUM FOR SHARED COMMUNICATION AND PROACTIVE CAMPUS CHANGE
}

David W. Schumann, Dorian Stiefel

University of Tennessee

Michelle Corvette

Goldsmiths, University of London

\author{
Chutney W. Guyton \\ North Carolina Central University
}

One problem that large, comprehensive universities often share is the lack of communication and synergistic creativity between units and services related to teaching and student learning. Moreover, large universities have difficulty creating and reinforcing needed change. This chapter provides a case study of a strategy for initiating and maintaining a university learning consortium. The consortium brings together center directors, faculty scholars, and administrators to operate as an independent think tank on campus. The members engage in dialogue, generate creative ideas, and design and propose policies and practices that reflect desired change.

$\mathrm{O}$

A number of consequences ensue when university units charged with faculty development work independently and do not communicate with one 
another. Obvious negative repercussions include duplication of services, lack of knowledge about other units, and missed opportunities to work together to better serve individual faculty needs. At a higher level, three problems emerge. First, the lack of community around teaching and learning leaves people unsupported and working alone. Second, important projects are not addressed, either because people do not have time or because the projects fall into the gaps between individuals' responsibilities; there is work that everyone means to handle but nobody does. Third, many of the teaching and learning problems require maturity and strategic thinking. For each of these problems, working together as a group produces far more creative alternatives than working individually. The remedy to these failures of communication is the learning consortium, described in this chapter, that provides faculty development leaders with expanded opportunities, collaborations, and leverage.

Many large public universities provide multiple support services focused on teaching and student learning: student success centers, teaching and learning centers, libraries, instructional technology (if independent of teaching and learning centers), centers for international education, public policy centers, organized outreach centers and programs, and housing (such as learning communities), for example. In addition, these large institutions have multiple structures with responsibility for curriculum to include central administration (often the provost), college administrators, and faculty senate representatives. In most cases, these services and structures often appear to work independently. By their very nature, such separate services and structures reinforce less-than-optimal between-group communication and decrease the potential for synergistic creativity.

One way to encourage increased communication across these learningfocused units and university structures is to create an entity that is inclusive of all relevant units and is focused on interactive dialogue. In 2008, the University of Tennessee initiated the Tennessee Teaching and Learning Center (TENN TLC). With a new center came the opportunity to create a vehicle to bring multiple units together, all involved in the support of teaching and student learning. The vehicle employed was a learning consortium (LC).

The overall purpose in establishing the consortium was twofold. First, it was thought that encouraging direct communication would increase understanding of roles and practices and contribute to intercenter communication, engagement, and potential for synergistic approaches to new initiatives. Second, such a representative group could consider some critical issues and concerns related to teaching and student learning and the related need for improvement and change. This chapter focuses on the 
supportive literature, purpose, design, membership, implementation and maintenance, and results to date of the University of Tennessee's learning consortium.

\section{Literature Review}

Consortia represent a sharing of governance among directors of centers, key faculty members, administrators, and graduate students collaborating as change agents to influence the culture and policies of an institution (Baron, 2006; Chism, 1998; Cox, 2001; Dawson, Mighty, \& Britnell, 2010; Howe \& Strauss, 2007; Lieberman \& Guskin, 2003; Marshall, 1999; Schroeder \& Spannagel, 2006). The concept of collaboration, the grouping and pairing of individuals for the purpose of achieving a goal by relying on each other, has been widely researched and advocated throughout the academic literature (Bruffee, 1993; Dawson, Britnell, \& Hitchcock, 2009; Garrison \& Vaughan, 2008; Gerlach, 1994; Kerka, 1997; Peters \& Armstrong, 1998; Saltiel, 1998; Wildavsky, 1986). Proponents of collaboration point out that the active exchange of ideas within small groups not only increases interest but may also promote critical thinking, greater effectiveness, efficiency, and a better campus environment (Gokhale, 1995; Kezar \& Lester, 2009; Mattessich \& Monsey, 1992). Likewise, collabora tion among individuals and groups who share a common vision is essential for developing, sustaining, and reshaping educational systems. Fullan $(1993,1995)$ observed that collaboration is necessary for ongoing learning; without collaborative skills and relationships, change can be a slow process.

Collaboration between faculty developers and support system staff can provide great value. Faculty members often travel from one center to another (for example, those for teaching and learning, library, and instructional technology), searching for the right tools to facilitate student learning in their classrooms. Many faculty scholars and administrators believe that integration and collaboration improve the quality of teaching, research, and service (Bakker, 1995; Clark, 1997; Garrison \& Akyol, 2009; Jenkins, 2000; Taylor, 2005). Integrated services bring together faculty members' teaching, research, and services more effectively (Colbeck, 1998; Ferren \& Stanton, 2004; Maehr \& Braskamp, 1986; Martin, Schermerhorn, \& Larson, 1989). Furthermore, integrated services reinforce the wise use of faculty resources, which ultimately benefits students and other beneficiaries of college and university work (Kezar \& Lester, 2009; Krahenbuhl, 1998). 


\section{Developing Commitment for a Learning Consortium}

As the inaugural director of the TENN TLC was interviewing for his position, it became apparent to him that the units responsible for various aspects of teaching and student learning were not provided the opportunities to communicate with one another. This led him to the idea of a learning consortium (LC) where center directors, creative faculty, and progressive administrators could have meaningful conversations and form joint ventures. To initiate the consortium at the university, the inaugural director identified key potential participants: other center directors (director-level individuals from the Student Success Center, University Libraries, Center for International Education, Office of Information Technology's Educational Support Group, and Howard H. Baker Jr. Center for Public Policy). He met with each one individually to discuss the idea of a learning consortium. Receptivity for the idea was universally strong.

The next step was to advise the provost's office of the desire to create the LC. Because three of the center directors were on the provost's staff, the idea was strongly supported by the central administration.

Once initial buy-in was established, a list was generated of other key administrators and faculty scholars who were deemed to be thought leaders and appropriate candidates for membership in the consortium. Drawing from the literature and research on collaboration (Bergman, 1992; Mattessich \& Monsey, 1992), careful attention was given to the selection and organization of the LC membership. An initial decision was also made to limit the group to fifteen members in order to keep it to a manageable size. In addition to the center directors, the remaining members of the LC were the associate dean of the College of Arts and Science (representing the largest college), the chair of the Faculty Senate Teaching Council, the assistant provost for student success (which included responsibility for student advising), and a set of innovative faculty involved in a high level of student engagement through experiential, collaborative, and distance learning pedagogies. Over the past three years, the group has added director representation from the Undergraduate General Education Committee, Undergraduate Policies Committee, graduate school, Chancellor's Honors Program, academic deans, Department of Student Housing, and university president's staff (systems level).

The rationale for identifying and adding key participants reflects several distinct needs that include campuswide representation, diverse information sources, knowledge of campus personnel, and the ability to facilitate action. More than a traditional university committee or council, 
the learning consortium mixes people at different job levels and from different types of units. Whereas administrative units are often brought together by a central administrator reflecting the responsibilities of that central administrator, the learning consortium was developed to reinforce the communication and collaboration between a combination of entities. Moreover, because the consortium does not have to operate as would a unit resembling a functional silo, its independent and broad-based nature represents more diverse thinking and the ability to consider a greater number of alternatives for forwarding the teaching and learning effort at the university.

\section{Learning Consortium Structure}

The structure of the learning consortium was developed over time with the input and involvement of a wide range of participants and perspectives.

\section{Stage I Meetings: Getting Started and a Strategic Plan}

To facilitate the collaborative approach, the learning consortium began meeting in October 2008 with the specific purpose of addressing concerns, issues, and activities related to the question of how students at the university learn best. In the initial meeting, the decision was made that all members would commit to being full participants in the consortium discussions and full collaborators in the design and implementation of actions, and they would have an equal voice regarding all group decisions. The role of the facilitator would be a shared responsibility among the group members.

The first meeting began with each person sharing his or her thoughts with regard to his or her own interest in the group and how each perceived its purpose. This facilitated a co-constructed understanding of shared mission and purpose. The initial facilitator, the TENN TLC inaugural director, reflected on the importance of maintaining mutual respect, trust, flexibility, openness, and shared communications. All agreed, and meetings were set at a three-week interval.

In order to open up the discussion and begin to understand the areas of concern that could be the focus of the learning consortium, the group participated in an affinity exercise where each member was asked to share the issues, thoughts, or activities that were important to improving an understanding of student learning. The results of the affinity exercise revealed a set of learning-related clusters: vision, support, incentives, learning advances, pedagogical research, communication, assessment, 
students, and faculty. It became apparent that a systematic planning approach (Kaufman \& Herman, 1991) was needed to address these interests. Between the first and second meeting, the results of the affinity exercise informed a working group that authored a strategic planning document. It was agreed that the strategic plan, which emphasizes collaborative decision making, should include the following components: developing a cocreated mission (purposes and beliefs), identifying appropriate objectives and respective strategies for addressing those objectives, and addressing the needs and issues derived from the affinity exercise.

During the second meeting, a significant amount of time was spent on refining the mission statement. It was clear that all members wanted to make sure the preferred language was correct because this statement would potentially represent the group with other university stakeholders. The following mission statement was adopted:

The purpose of the University of Tennessee Learning Consortium (UTLC) is to support and facilitate the enhancement of learning at the University of Tennessee through the purposeful interaction of individual learning facilitators across the UT faculty and administration. The UTLC is comprised of learning related center directors, faculty, and college administrators directly involved in the design and delivery of creative learning pedagogy.

The UTLC will provide an independent voice offering guidance and support to the University community in order to create a better learning environment. By working as a group and through partnerships with other learning facilitators in the University community and outside of the University, the UTLC will generate ideas, approaches, processes, research and propose policy that addresses the state of current and future learning. This accumulated knowledge will be disseminated to the University community through a number of means (e.g., workshops, presentations, papers, articles, workbooks). The UTLC will also foster continuous improvement of teaching and learning through ongoing review and discussion of each other's activities, practices, and policies, as well as other related teaching and learning initiatives. It is envisioned that this will lead to creation of a culture of teaching and learning excellence that is facilitated, integrated, and reinforced throughout the University community.

During the second meeting, members suggested changes to the strategic plan such as editing the objectives, the language of the strategies, and the 
order and specifics of the tactics. In the third and final meeting of stage I, each objective and the resultant strategies and tactics were examined closely and revised in final form as necessary. The following objectives were finalized:

1. Create a professional learning community environment within the UTLC where all perspectives can be voiced and considered.

2. Research new integrated learning strategies and the changing characteristics and needs of our students.

3. Develop new pedagogical models and inform critical stakeholders.

4. Improve assessment of teaching and learning.

5. Create cultural change within units to reinforce engagement in the understanding and facilitation of student learning.

Given that each objective had multiple strategies and each strategy had one or more tactics, implementing the plan required leadership from the learning consortium members. Thus, during the third meeting, each person voiced one or more objectives in which he or she was willing to lead a working group that would address the needed strategies. It was believed that these working groups should be inclusive and reach out to others in the university community.

During this first stage of meetings it was also important to discuss the specific products from the work. The group decided on four major outputs:

o Sharing creative ideas within the LC that could be adopted relatively quickly by one or more of the centers as well as by individual faculty participants

- The creation by each working group of a product (for example, a white paper, guide, checklist) that would provide policy or practice recommendations

- The use of specific information from these products and, where appropriate, the development of faculty development modules for professional training (for example, workshops, presentations, papers, articles, and workbooks)

- The need to pool both personnel and financial resources, as appropriate, to be used to bring in external speakers and provide faculty and students with meaningful cosponsored learning activities 


\section{Stage II Meetings: Implementation and Continued Generation of Ideas}

After completion of the initial strategic planning work came the need to develop a structure for all subsequent meetings. It was decided that all meetings would last ninety minutes. Two main types of presentation content were envisioned. The first included working group updates, sharing new ideas, reports on recent and forthcoming events, and presentations of existing learning and faculty development strategies. The second included meetings that would focus primarily on revising a targeted product.

Although the objectives in the strategic plan were broad, several initial work groups reflecting one or more objectives were initiated, and more have been generated over the past three years of the learning consortium's existence.

Finally, and perhaps of greatest importance, meetings are an excellent venue for ongoing conversations about teaching and learning topics. Every meeting begins with an update from two or three of the center directors or other members, and each update sparks further conversation and new ideas. Many of these ideas reflect ways in which two or more of the represented units or members can work together more effectively. This represents the initial reason for forming the consortium, and it now appears to be a highly valued aspect.

Discourse in the learning consortium is advanced through problemsolving activities, playful discussions, and challenging questions. Fundamentally, respect for each other and the mission of improving teaching and learning influences everyone's approach to the meetings and each other. The collaborative philosophy of the group was developed early and is reinforced consistently by members and the facilitator.

This approach to discourse and collaboration leads to new insights by allowing people to work together, play off each other, share multiple perspectives, and incorporate different views. One early insight was the value of listening to what people had to say, which in turn provided individuals with new ways of thinking; another is the importance of attempting to carry the conversations that learning consortium members are having beyond the group. Finally, members admit that multiple ways to effect change and multiple outcomes can be acceptable. In one case, discussions in the group provoked a proposal for a teaching academy consisting of creative faculty across campus who meet together and then return to their departments with new ideas and potential guest speakers. Membership in the teaching academy will rotate over time to include different departments and faculty. 


\section{Examples of the Learning Consortium Work and Results to Date}

One issue that was raised early in the learning consortium's existence was the development of consistent standards for two emerging types of pedagogical delivery: online learning and service-learning. Two working groups were formed to review the existing literature, benchmark other schools, and author appropriate documents for faculty guidance. The former (types of online delivery) resulted in a comprehensive checklist for faculty of steps to consider and needs to address. This checklist for service-learning was presented to several faculty leaders with significant online teaching experience, then vetted by the consortium, and revised; it is now available on multiple university Web sites. This checklist served as a guiding structure for a summer institute in course design, a collaborative effort of two units represented in the consortium, employing three tracks for faculty (face-to-face, blended or hybrid, and pure online).

The focus on service-learning has sparked two initiatives. First, the learning consortium facilitator was asked by the provost's office to lead a task force to develop a business plan around service-learning for the campus. This task force, composed in part of learning consortium members, authored a proposal for a new center for community engagement that would incorporate service-learning but go much further to serve as a portal between the university and the community. This plan was vetted by the learning consortium members, was submitted to the provost, and is now under consideration for funding. Second, the emerging checklist for servicelearning has spurred multiple faculty training workshops on the topic.

In addition, the learning consortium has made significant progress in addressing one of its initial objectives, assessment of teaching effectiveness and of student learning. To do so, it established two committees, both of which created documents useful to the university. First, a peer teaching evaluation guide was researched and authored. This document was approved by the provost and faculty senate as a guide and was disseminated to all department heads. Numerous anecdotal comments from department heads reflect that this document was essential, welcomed, and now widely employed across the various units on campus. Second, and perhaps the most meaningful learning consortium initiative to date, is addressing the challenging topic of improving institutional assessment of learning. A working group of the consortium collected research on the topic and developed an initial set of recommendations to the vice provost for academic programs. The learning consortium working group leader was then asked to convene a larger group as an official provost's task 
force on the topic. This group, working with the vice chancellor overseeing university accreditation, developed a comprehensive set of recommendations that connects directly to accreditation requirements of the university. This proposal has been accepted by the vice chancellor in charge of our upcoming accreditation process. As a result, the teaching and learning center has a search under way for an assistant director for research, assessment, and program evaluation. A primary function of this position is to lead department-level faculty training that directly addresses assessment of learning concerns.

The learning consortium has continued to use the first meeting of each academic year to generate new ideas. For example, at the beginning of the second year, the consortium voiced a desire to engage with students. A student forum on learning (SFL) was initiated under the sponsorship of the Tennessee Teaching and Learning Center (TLC). The SFL became active, meeting every three weeks, and it settled on two purposes. First, it serves to inform both the TLC and the learning consortium about students' needs regarding teaching and learning. Students from the group are invited to present their thoughts to the TLC staff and the learning consortium on a regular basis and react to the learning consortium members' ideas. Second, the SFL, with the learning consortium's encouragement, has generated its first white paper focused on student perceptions and student needs. This white paper was vetted by the learning consortium members, who proposed a widespread dissemination of the paper across campus. The paper was then submitted to the provost. Not only has the paper received significant attention by central administration and been widely disseminated to the administration, but the SFL has been asked by numerous groups to make a presentation. Furthermore, the provost has asked that members of the SFL serve as student representatives on key strategic planning committees and task forces. The SFL, with support and shared dialogue from the learning consortium, provides another vehicle for student voices to be heard.

The learning consortium is currently pursuing a number of projects:

o A teaching certification program for Ph.D. students (joint effort between the TENN TLC and the graduate school)

o A university cultural statement of shared values (for example, about civility, respect, desire to learn, and desire to improve) of those who study or work at the university

- A plan to increase the numbers of students studying abroad

- A common "university syllabus" available for faculty to include within course syllabi 
- An assessment of the learning consortium's impact, including a discussion of the strengths and weaknesses of the University of Tennessee learning environment (broadly defined)

\section{Conclusion: Potential Constraints and Review of Benefits}

The development of a learning consortium, which in theory sounds like a logical idea to improve communication and take a more active role as a change agent within the university, contains certain inherent constraints and threats. Given the multiple roles the learning consortium members have on campus, each is extremely pressed for time. This has manifested itself in occasional absence from meetings and delay in completing projects. The consortium has addressed this constraint in three ways. It has increased its membership to create more working capacity. Next, it employs a few hours of time from a TENN TLC staff member who is responsible for taking and distributing minutes, arranging the schedule of meetings, and facilitating communication. Finally, it charged the consortium facilitator with keeping a careful eye on the progress of each working group and encouraging movement as appropriate.

A potential threat that exists is the ongoing question of how willing other campus entities are to allow a relatively independent think tank to exist on campus and have significant input into change. Several factors can mitigate this threat. Keeping both the provost's office and the faculty senate apprised of the learning consortium's activities is critical to sustaining this group's effectiveness and importance on campus. Over time, as a result of the quality of the products provided, trust can develop. Furthermore, by having key people from both faculty and administration as members of the consortium, the threat of a movement to centralize this effort under a central administrator is diminished although never erased. As the consortium becomes more visible with regard to suggesting practices and policy that guide change, it is possible that a reporting structure may be required. However, to date, the learning consortium has operated independent of a direct reporting line.

To best respond to this threat, the consortium is considering an assessment of its impact. While individual centers assess their activities as do cofacilitated projects between centers, no overall assessment of impact has been undertaken yet. As this chapter goes to press, the consortium has determined measures of assessment of impact that reflect adoption of recommendations and the extent of the adoption.

While certain constraints and threats are likely to exist for a learning consortium, four significant benefits can be identified and outweigh any 
concerns. First, by meeting on a regular basis, center directors are able to have a time set aside to communicate with one another and share new ideas that can potentially lead to integrated activities (such as shared workshops and shared funding of events) as well as improvement of the base services each center provides. Second, by recruiting innovative and creative participants, the group can serve as a think tank with regard to improvement of teaching and learning. New ideas can be discussed and considered for action. Third, the university benefits through the efforts of the group to consider needed changes in practices and policies. Fourth, through careful composition and inclusion, numerous units and individuals are represented, generating a wealth of perspectives and creative ideas.

A question to be posed is whether the learning consortium model transfers to multiple types of higher education institutions. We believe that the concept is generalizable across all types of colleges and universities. Although the learning consortium described in this chapter was initiated at a research-intensive institution, the underlying value proposition reflects a desire for joint communication and collaboration among entities to continuously improve the state of student learning. It seems logical that this value should be held in common across all types of higher education institutions. Such efforts can only enhance the student educational experience.

In sum, this chapter has offered faculty development leaders insights and a pathway for designing, promoting, and implementing the learning consortium concept. During its three-year existence, the University of Tennessee's learning consortium has engaged in numerous important activities and has created meaningful changes important to teaching effectiveness and student learning. It has intentionally and carefully built its membership to reinforce inclusivity. Each year it generates new ideas and builds on previous ones. The group remains energetic and highly focused. The philosophy of strategic inclusion, openness to ideas, the proactive nature of the group, and the creativity that comes from collaboration make it a desirable organizational entity on which to serve.

\section{REFERENCES}

Bakker, G. (1995, March 17). Using "pedagogical-impact statements" to make teaching and research symbiotic activities. Chronicle of Higher Education, B3.

Baron, L. (2006). The advantage of a reciprocal relationship between faculty development and organizational development in higher education. In S. Chadwick-Blossey \& D. R. Robertson (Eds.), To improve the 
academy: Resources for faculty, instructional, and organizational development, Vol. 24 (pp. 29-43). San Francisco, CA: Jossey-Bass/Anker.

Bergman, A. (1992). Lessons for principals from site-based management.

Educational Leadership, 50(1), 48-51.

Bruffee, K. A. (1993). Collaborative learning, higher education, interdependence and the authority of knowledge. Baltimore, MD: Johns Hopkins University Press.

Chism, N.V.N. (1998). The role of educational developers in institutional change: From basement office to the front office. In M. Kaplan \& D. Lieberman (Eds.), To improve the academy: Resources for faculty, instructional, and organizational development, Vol. 17 (pp. 141-153). San Francisco, CA: Jossey-Bass/Anker.

Clark, B. R. (1997). The modern integration of research activities with teaching and learning. Journal of Higher Education, 68, 241-255.

Colbeck, C. L. (1998). Merging in a seamless blend: How faculty integrate teaching and research. Journal of Higher Education, 69(6), 647-671.

Cox, M. (2001). Faculty learning communities: Change agents for transforming institutions into learning organizations. In D. Lieberman \& C. Wehlburg (Eds.), To improve the academy: Resources for faculty, instructional, and organizational development, Vol. 19 (pp. 69-93). San Francisco, CA: Jossey-Bass/Anker.

Dawson, D., Britnell, J., \& Hitchcock, A. (2009). Developing competency models of faculty developers: Using world café to foster dialogue. In L. Nilson \& J. E. Miller (Eds.), To improve the academy: Resources for faculty, instructional, and organizational development, Vol. 28 (pp. 3-24). San Francisco, CA: Jossey-Bass/Anker.

Dawson, D., Mighty, J., \& Britnell, J. (2010). Moving from the periphery to the center of the academy: Faculty developers as leaders of change. In J. McDonald \& D. Stockley (Eds.), New directions for teaching and learning: No. 122. Pathways to the profession of educational development (pp. 69-78). San Francisco: Jossey-Bass.

Ferren, A. S., \& Stanton, W. W. (2004). Leadership through collaboration: The role of the chief academic officer. San Francisco, CA: Jossey-Bass.

Fullan, M. G. (1993). Change forces: Probing the depth of educational reform. New York: Falmer.

Fullan, M. G. (1995). The limits and the potential of professional development. In T. R. Guskey \& M. Huberman (Eds.), Professional development in education: New paradigms and practices (pp. 253-267). New York: Teachers College Press.

Garrison, D. R., \& Akyol, Z. (2009). Role of instructional technology in the transformation of higher education. Journal of Computing in Higher Education, 21(1), 19-30. 
Garrison, D. R., \& Vaughan, N.D. (2008). Blended learning in higher education: Framework, principles, and guidelines. San Francisco, CA: Jossey-Bass. Gerlach, J. M. (1994). Is this collaboration? In K. Bosworth \& S. J. Hamilton (Eds.), New directions for teaching and learning: No. 59. Collaborative learning: Underlying processes and effective techniques (pp. 5-14). San Francisco, CA: Jossey-Bass.

Gokhale, A. A. (1995). Collaborative learning enhances critical thinking. Journal of Technology Education, 7(1), 22-30.

Howe, N., \& Strauss, W. (2007). Millennials go to college (2nd ed.). Great Falls, VA: Lifecourse Associates.

Jenkins, A. (2000). The relationship between teaching and research: Where does geography stand and deliver? Journal of Geography in Higher Education, 24(3), 325-351.

Kaufman R., \& Herman, J. (1991). Strategic planning in education: Rethinking, restructuring, revitalizing. Lancaster, PA: Technomic Publishing Company. Kerka, S. (1997). Developing collaborative partnerships. Columbus, OH: ERIC Clearinghouse on Adult, Career, and Vocational Education, Center on Education and Training for Employment, Ohio State University.

Kezar, A. J., \& Lester, J. (2009). Organizing bigher education for collaboration: A guide for campus leaders. San Francisco, CA: Jossey-Bass.

Krahenbuhl, G. S. (1998). Faculty work: Integrating responsibilities and institutional needs. Change, 30(6), 18-25.

Lieberman, D. A., \& Guskin, A. F. (2003). The essential role of faculty development in new higher education models. In C. M. Wehlburg \& S. Chadwick-Blossey (Eds.), To improve the academy: Resources for faculty, instructional, and organizational development, Vol. 21 (pp. 257-272). San Francisco, CA: Jossey-Bass/Anker.

Maehr, M. L., \& Braskamp, L. A. (1986). The motivation factor: A theory of personal investment. Lexington, MA: Heath.

Marshall, W.J. (1999). University service. In V. Bianco-Mathis \& N. Chalofsky (Eds.), The full-time faculty handbook (pp. 113-128). Thousand Oaks, CA: Sage.

Martin, T. N., Schermerhorn, J. R., \& Larson, L. L. (1989). Motivational consequences of a supportive work environment. In M. L. Maehr \& C. Ames (Eds.), Advances in motivation and achievement (pp. 179-214). Greenwich, CT: JAI Press.

Mattessich, P. W., \& Monsey, B. R. (1992). Collaboration: What makes it work. St Paul, MN: Amherst H. Wilder Foundation.

Peters, J. M., \& Armstrong, J. L. (1998). Collaborative learning: People laboring together to construct knowledge. In I. R. Saltiel, A. Sgroi, \& R. G. Brockett 
(Eds.), New directions for adult and continuing education: No. 79. Using consultants to improve teaching (pp. 75-85). San Francisco: Jossey-Bass.

Saltiel, I. M. (1998). Defining collaborative partnerships. In I. R. Saltiel, A. Sgroi, \& R. G. Brockett (Eds.), New directions for adult and continuing education: No. 79. Using consultants to improve teaching (pp. 5-11). San Francisco, CA: Jossey-Bass.

Schroeder, U., \& Spannagel, C. (2006). Supporting the active learning process. International Journal on E-Learning, S(2), 245-264.

Taylor, K. L. (2005). Academic development as institutional leadership: An interplay of person, role, strategy, and institution. International Journal for Academic Development, 10(1), 31-46.

Wildavsky, A. B. (1986). Budgeting: A comparative bistory of budgetary processes. New Brunswick, NJ: Transaction Books. 